\title{
COPING WITH STRESS IN THE WORKPLACE
}

\author{
JANINE D OOSTHUIZEN \\ Jopie van Rooyen \& Partners \\ South Africa \\ BURGER VAN LILL \\ School of Management Studies, \\ University of Cape Town \\ South Africa \\ Correspondence to: Burger van Lill \\ e-mail: burger.vanlill@uct.ac.za
}

\begin{abstract}
The researchers investigated a simplified process model, a so-called salutogenic approach, of coping with stress in the workplace. Two constructs of salutogenic functioning, namely sense of coherence and locus of control (three dimensions: internal, external locus and autonomy), as well as the stress levels of 240 employees from a parastatal organisation were measured. As expected, individuals with a stronger sense of coherence and a stronger internal locus of control experienced lower levels of stress and vice versa. Nevertheless, in a regression analysis only the sense of coherence and external locus of control variables contributed significantly to variance in the criterion variable stress.
\end{abstract}

Keywords: stress, workplace, salutogenic approach, sense of coherence, parastatal organisation

South Africans from all walks of life experience abnormally high levels of stress that often manifest in typical emotional behaviour (Van Zyl \& Bester, 2002). From South African and international literature it is evident that stress is also common in the workplace with serious consequences for employers and employees (Atkinson, 2004; Cilliers \& Kossuth, 2002; Dhaniram, 2003; Le Feure, Matteny \& Kolt, 2003; Lowe, 2004; Shevel, 2007; Recupero, 2003). According to Van Zyl and Bester (2002), elevated stress levels within South African organisations often occur as a result of a scarcity of high-level human resources, managers and professionals that are under great pressure and skill shortages that create exceptional pressures on technicians and skilled workers.

\section{Definition of stress}

As is the case with most constructs in use in psychology, researchers employ a wide variety of conceptual definitions of the stress construct (cf. Hart \& Cooper, 2001). Luthans (2002) refers to the work of Ivancevich and Matteson and that of Beehr and Newman for his conceptual definition of stress.

According to Ivancevich and Matteson (cited in Luthans, 2002, p. 396), stress is "an adaptive response, mediated by individual differences and/or psychological processes, that is a consequence of any external (environmental) action, situation, or event that places excessive psychological and/or physical demands on a person".

Luthans (2002, p. 396) emphasises the following three critical aspects of Ivancevich and Matteson's definition: 1) stress is the response or reaction to a situation or event, it does not refer to the stimulus or stressor i.e. the situation or event itself; 2) stress can be moderated or mediated by individual differences, and 3) stress is a response to "excessive psychological and/or physical demands,' because only special or unusual situations (as opposed to minor life adjustments) can really be said to produce stress".

In their study Beerh and Newman (in Luthans, 2002, p. 396) add a workplace dimension and define job stress as "a condition arising from the interaction of people and their jobs and characterized by changes within people that force them to deviate from their normal functioning". Luthans (2002, p. 396) amalgamates the two definitions above very elegantly to define stress within an organisational psychological context: "an adaptive response to an external situation that results in physical, psychological, and/or behavioral deviations for organizational participants".

Finally, Luthans (2002) emphasises that stress is not simply anxiety or nervous tension, nor is it necessarily something damaging or bad that should be avoided at all costs. Eustress represents a positive response to stress that should be encouraged, while distress represents a negative response that should be avoided or ameliorated.

\section{Process theory of managing stress}

According to Hart and Cooper (2001, p. 96), researchers have developed a number of process theories to provide a more coherent framework for understanding stress. A common characteristic of most of these process theories is that they are based on a transactional approach that treats stress as a dynamic process operating between an individual and his/her environment (Hart \& Cooper, 2001). These authors state that the dynamic, reciprocal nature of the relationships between personal and environmental variables, distinguishes transactional models from other, more static or unidirectional ones.

Hart and Cooper (2001) discuss two other approaches to the dynamic process theory of stress, namely the cognitive-rational approach and the dynamic equilibrium theory. In the cognitiverational approach the appraisal of and coping with stress are addressed, while according to the dynamic equilibrium theory, stress results from disequilibrium among the variables (personal as well as environmental characteristics) that link individuals with their environments.

From their review of literature and research, Hart and Cooper (2001) subsequently developed a comprehensive integrated organisational health framework that focuses simultaneously on the wellbeing of the employee and the performance of the organisation, where employee wellbeing and organisational performance are both influenced by a combination of individual and organisational characteristics. 
Although Hart and Cooper's (2001) process model is very comprehensive, it is also extremely complex, comprising 16 variables which represent personal and organisational characteristics, employee wellbeing and organisational performance, plus all the interrelations among them. Thus, for the present study Luthans' definition of stress (see above) as well as a simplified version of a process model for coping with stress was taken into consideration. The researchers employed the so-called salutogenic model and retained constructs such as employee wellbeing, coping with stress, a dynamic equilibrium, cognitive-rational decision making and reacting to the environment in the present study.

\section{Salutogenic functioning}

The salutogenic model derives its name from a combination of the Latin word 'salus' meaning health and 'genesis' from Greek referring to origins (Antonovsky, 1979). In the salutogenic model, Antonovsky (1979) explains that the emphasis is on the origins of health rather than on illness or disease as is the case with pathogenic models.

The salutogenic approach accepts the inevitability of stressors in daily life generally and the workplace specifically, and the fact that human beings have to cope with the ensuing stress in some way or another. Individuals are able to cope with stress and take responsibility for their own health in an environment that allows them to act autonomously (Dhaniram, 2003). According to Viviers (1998a), many physiological and psychological illnesses can be controlled or even prevented, by making individuals aware of how to function optimally whenever they are required to cope with stress at work and home. By developing a salutogenic orientation both employees and organisation can benefit.

Antonovsky (1979) explains that individuals can be positioned on a continuum from a negative pole representing 'dis-ease', to a positive pole representing 'health-ease', where the individual's position is determined by an interaction of opposing forces of environmental threats (stressors), the individual's degree of resistance (generalised resistance resources (GRRs)) and the strength of his/her sense of coherence (SOC). Despite the inevitability and pervasiveness of stressors, many individuals manage to control their stress and may even thrive under extremely difficult circumstances. Some individuals appear to be coping with the negative stressors, but are healthier than others because they have learnt to live with this kind of stressor. As such these individuals have learned to turn their struggle into an advantage by taking responsibility for their health when the environment allows them to act autonomously (Dhaniram, 2003)

Smith (2002) is of the opinion that individuals' outlook on life forms the basis of certain processes in the human brain. These processes function as salutogenic mechanisms and as such they are beneficial to the individual's health. For example, an individual who believes that things will work out as well as can be expected may be able to cope well despite stressful situations and maintain his/her good health in this way. Referring to examples such as faith healing and the placebo effect, Smith (2002) believes that these perspectives do not necessarily have to be realistic or rational to be salutogenic. Individuals, who employ a salutogenic approach to stressors, are less likely to develop physical and mental illnesses as their homeostatic balance is restored through the use of coping mechanisms, which in turn leads to optimal functioning under stress (Viviers, 1998b).

According to Kossuth and Cilliers (2002), salutogenic functioning is characterised by a cognitive level (individuals can perceive environmental stimuli in a positive and constructive way and use the information to facilitate effective decision making), by an affective level (individuals are maturely committed to life, self-aware, confident and self-fulfilled) and by a motivational level (individuals are intrinsically motivated, they perceive stimuli as a personal challenge and they direct their energy at coping, solving problems and achieving results).

Researchers have isolated a number of salutogenic variables that may act as coping mechanisms in stressful situations as they focus on health as opposed to disease. They equip individuals to deal more effectively with stress and include factors such as hardiness, coping, social support, religion, happiness, humour, love and selective perception (Smith, 2002). Dhaniram (2003) identifies four distinct, but to some extent overlapping, salutogenic constructs prevalent in current research, namely sense of coherence (Antonovsky, 1979), hardiness (Kobasa, 1979), locus of control (Rotter, 1966) and learned resourcefulness (Rosenbaum, 1988).

\section{Sense of coherence (SOC)}

Antonovsky (1979, p. 123) defines SOC as "a global orientation that expresses the extent to which one has a pervasive, enduring though dynamic feeling of confidence that one's internal and external environments are predictable and that there is a high probability that things will work out as well as can reasonably be expected".

\section{Hardiness}

Florian, Mikulincer and Taubman (1995, p. 694) define hardiness as "a constellation of personality characteristics that function as a resistance resource during the encounter with stressful life events".

\section{Locus of control (LOC)}

According to Rotter (1990), internal locus of control refers to the degree to which individuals expect the reinforcement or outcome of their behaviour to be contingent on their own acts or characteristics. Conversely, external LOC refers to the extent to which individuals expect reinforcement or outcomes to be unpredictable, a function of chance, luck or fate and/or to be under control of other powerful persons. Locus of control is a relatively global characteristic, which is relatively stable over time and situations (Rotter, 1966).

\section{Learned resourcefulness}

Rosenbaum (1988) describes learned resourcefulness as a set of complex behaviours, cognitions and emotions that are in constant interaction with an individual's physical and social environment. It is learned from birth, serves as coping skill in stressful situations and also provides a framework for further learning (Rosenbaum, 1980). According to Rosenbaum and Jaffe (1983), learned resourcefulness may include enabling skills such as self-monitoring of internal events, self-evaluative skills and the ability to verbalise and label feelings. On the other hand, in the learned helplessness model, individuals learn that it is futile to respond in uncontrollable situations and such a perception is then generalised to controllable situations.

\section{Investigating a salutogenic model that includes sense of coherence and locus of control to manage stress}

Although the four salutogenic constructs mentioned above are identified as distinct variables, they do overlap in terms of their definitions as well as research findings (cf. Fontaine, Manstead \& Wagner, 1993; Kossuth \& Cilliers, 2002; Kravetz, Drory \& Florian, 1993; Oosthuizen, 2006). For the sake of simplicity and for practical reasons (keeping the questionnaire to a manageable length), the present study was restricted to a salutogenic model based on the relationships between sense of coherence, locus of control and stress.

Antonovsky (1987) explains that SOC refers to a basic orientation that enables the individual to consider the best coping strategy for a specific problem. Rather than focusing on 
specific responses and specific behaviour, a sense of coherence alleviates life stress by addressing the general quality of an individual's behaviour (Flannery \& Flannery, 1990). A strong sense of coherence usually results in a feeling of confidence in coping with life stress (Oosthuizen, 2006).

Locus of control refers to the extent to which individuals perceive that either they or external factors have control over a given situation (Rotter, 1990). A perception of exercising control over a situation facilitates the development of an extensive repertoire of responses to stress, which can be utilised in most threatening situations (Rosenbaum \& Jaffe, 1983). Perceived control contributes to a feeling of optimism, specifically in stressful situations, which in turn may result in effective coping and matching demands and resources (Fontaine et al., 1993).

\section{Hypotheses}

Because the South African population in general and employees in particular are experiencing high levels of stress (Van Zyl \& Bester, 2002), the researchers expected participants in the present study also to exhibit relatively high levels of stress.

As sense of coherence and locus of control are mechanisms that assist people to deal with stress, the researchers expected significant relationships between these variables. It was expected that individuals with a relatively high sense of coherence will report relatively low stress levels and vice versa. It was also expected that individuals with a relatively high internal locus of control would experience relatively low stress levels and conversely, those with a relatively low internal locus of control would experience high levels of stress. In line with the latter hypothesis, we expected a direct relationship between external locus of control and stress.

It was also expected that as predictors the salutogenic variables sense of coherence and locus of control could be used to explain a significant proportion of variance in the criterion variable stress.

\section{RESEARCH DESIGN}

\section{Research approach}

A quantitative relational approach was followed where the statistical relationships among the relevant variables were analysed. The researchers also attempted to predict variance in the criterion variable stress on basis of the salutogenic variables, namely sense of coherence and locus of control.

\section{Participants}

In total 677 questionnaires were distributed to all members of a parastatal organisation in the transport industry in the Western Cape. Two hundred and forty employees, 159 males $(66.3 \%)$ and 81 females (33.7\%), completed and returned the questionnaires, which number represents about $35 \%$ of the population of employees.

The age distribution, job levels and racial composition of the sample are represented in Tables 1 to 3 below.

\section{Measuring instruments}

Experience of Work and Life Circumstances Questionnaire (WLQ)

The WLQ is a self-rating instrument measuring stress within and outside the work situation. It has been standardised for South African conditions to measure the level and causes of stress for individuals with a reading and writing ability of Grade 10. In the manual coefficients of internal consistency (Kuder Richarson 8) and test-retest reliability ranging from 0.83-0.92 and from 0.62-0.80 respectively are given and the construct validity is also acceptable (see Van Zyl \& Van der Walt, 1991; 1994).
TABLE 1

Age distribution of the sample of employees

\begin{tabular}{lrr}
\hline AGE GROUPS & FREQUENCY & PERCENTAGE \\
\hline $18-24$ years & 9 & 3.8 \\
$25-30$ years & 27 & 11.3 \\
$31-40$ years & 66 & 27.5 \\
$41-49$ years & 66 & 27.5 \\
50 years and above & 72 & 30.0 \\
\hline
\end{tabular}

TABLE 2

Job levels of the sample of employees

\begin{tabular}{lrr}
\hline JOB LEVELS & FREQUENCY & PERCENTAGE \\
\hline Junior & 146 & 60.8 \\
Supervisor & 6 & 2.5 \\
Middle & 58 & 24.2 \\
Senior & 23 & 9.6 \\
Executive & 7 & 2.9 \\
\hline
\end{tabular}

TABLE 3

Racial composition of the sample of employees

\begin{tabular}{lrr}
\hline ETHNIC ORIGIN & FREQUENCY & PERCENTAGE \\
\hline African & 46 & 19.2 \\
Coloured & 70 & 29.2 \\
Indian & 5 & 2.1 \\
White & 116 & 48.3 \\
Not indicated & 3 & 1.3 \\
\hline
\end{tabular}

TABLE 4

Descriptive statistics for stress levels as measured by the Experience of Work and Life Circumstances Questionnaire

\begin{tabular}{lr}
\hline N & 240 \\
Mean & 79.42 \\
Median & 75.50 \\
Mode & 64 \\
Standard deviation & 22.77 \\
Skewness & 1.25 \\
Kurtosis & 2.49 \\
Cronbach's $\alpha$ & 0.94 \\
Minimum & 40 \\
Maximum & 175 \\
\hline
\end{tabular}

\section{Orientation to Life Questionnaire (OLQ)}

The construct sense of coherence was measured with the OLQ, a self-report instrument that evaluates an individual's tendency to apply coping mechanisms. The higher an individual's score on the OLQ, the stronger his/her sense of coherence. The instrument has a high internal consistency with Cronbach's alpha coefficients ranging from $0.84-0.93$ and test-retest reliabilities ranging from 0.41-0.97 (Antonovsky, 1987) and its construct validity is acceptable (Dhaniram, 2003).

\section{Locus of Control Inventory ( $\mathrm{LCI}$ )}

The LCI was developed in South Africa to measure the degree to which individuals perceive their ability to influence or control the world around them. The constructs external locus of control and internal locus of control actually do not refer to bipolar opposites, but rather to independent constructs (Schepers, 2005). Three dimensions are measured, namely internal locus of control, external locus of control and autonomy (Schepers, 2005). Acceptable internal consistency coefficients with Cronbach's alphas for internal control of 0.84, external control of 0.88 and autonomy of 0.87 are reported by Pretorius (2004) and the construct validity of the LCI is also acceptable (Pretorius, 2004; Schepers, 2005).

\section{Procedure}

The set of questionnaires comprised a biographical questionnaire developed for the study and the three self- 
administered questionnaires, namely the Experience of Work and Life Circumstances Questionnaire, the Orientation to Life Questionnaire and the Locus of Control Inventory. For those who could attend, the questionnaires were administered in small group settings. The supervisors and managers of those who could not participate in the small group assessments due to work commitments received and distributed the questionnaires among their employees. Eventually all the completed forms were collected by a researcher.

\section{RESULTS}

\section{Stress as measured by the Experience of Work and Life} Circumstances Questionnaire (WLQ)

The WLQ consists of a scale of 40 five-point items, therefore scores can range from a minimum of 40 to a maximum of 200. A score of 80 or above reflects a high stress level (Oosthuizen, 2006).

The responses of the present sample of employees are summarised in Table 4. As the distribution of the scores of the 240 participants is positively skewed (skewness $=1.25$ ) and the median is 75.50 and the mean is $79.42(\mathrm{SD}=22.77)$, it is clear that most of the participants reported relatively low levels of stress.

\section{Sense of coherence as measured by the Orientation of Life} Questionnaire (OLQ)

The responses of the present sample of employees are summarised in Table 5. The OLQ is a scale of 29 sevenpoint items ranging from a minimum of 29 to a maximum of 203. Jackson and Rothmann (2001) reported a mean sense of coherence score of 131.20 with a standard deviation of 20.62 for 100 participants from a South African health services institution. As the distribution of the scores of the 233 participants is slightly positively skewed (skewness $=0.17$ ) and the median is 133 (mean $=134.88, \mathrm{SD}=21.76$ ), it is clear that most of the participants reported relatively high levels of sense of coherence.

\section{Locus of control as measured by the Locus of Control Inventory (LCI)}

The descriptive statistics of the different dimensions of locus of control as measured by the LCI, namely internal locus of control, external locus of control and autonomy, are discussed in this section and summarised in Table 6.

\section{Internal locus of control}

The responses of the present sample of employees are summarised in Table 6 . This scale comprises 28 seven-point items ranging from a minimum of 28 to a maximum of 196 . Jackson and Rothmann (2001) reported a mean internal locus of control score of 148.91 with a standard deviation of 13.62 for 101 participants from the South African Police Service. As the distribution of the scores of the 240 participants is negatively skewed (skewness $=-0.97$ ) and the median is 156 with a mean of 149.51 ( $\mathrm{SD}=28.31)$, it is clear that most of the participants reported relatively high levels of internal locus of control.

\section{External locus of control}

The responses of the present sample of employees are summarised in Table 6 . This scale consists of 26 seven-point items ranging from a minimum of 26 to a maximum of 182 . Jackson and Rothmann (2001) reported a mean external locus of control score of 85.79 with a standard deviation of 19.16 for 101 participants from the South African Police Service. As the distribution of the scores of the 240 participants is slightly negatively skewed (skewness $=-0.09$ ) and the median is 100 with a mean of $99.34(\mathrm{SD}=23.16)$, it is clear that most of the participants reported relatively high levels of external locus of control.
TABLE 5

of Coherence as measured by the Orientation of Life Questionnaire

Descriptive statistics for Sense

\begin{tabular}{lr}
$\mathbf{N}^{*}$ & 233 \\
Mean & 134.88 \\
Median & 133 \\
Mode & 131 \\
Standard deviation & 21.76 \\
Skewness & 0.17 \\
Kurtosis & -0.07 \\
Cronbach's $\alpha$ & 0.87 \\
Minimum & 63 \\
Maximum & 188 \\
\hline
\end{tabular}

* Not all participants completed the OLQ

TABLE 6

Descriptive statistics for Internal Locus of Control, External Locus of Control and Autonomy as measured by the Locus of Control Inventory

\begin{tabular}{lrrr}
\hline $\begin{array}{l}\text { DESCRIPTIVE } \\
\text { STATISTICS }\end{array}$ & $\begin{array}{l}\text { INTERNAL LOCUS } \\
\text { OF CONTROL }\end{array}$ & $\begin{array}{l}\text { EXTERNAL LOCUS } \\
\text { OF CONTROL }\end{array}$ & $\begin{array}{l}\text { AUTONOMY } \\
\text { N }\end{array}$ \\
Mean & 240 & 240 & 240 \\
Median & 149.51 & 99.34 & 170.10 \\
Mode & 156 & 100 & 175 \\
Standard deviation & 177 & 109 & 190 \\
Skewness & 28.31 & 23.16 & 28.99 \\
Kurtosis & -0.97 & -0.09 & -0.46 \\
Cronbach's $\alpha$ & -0.43 & -0.05 & -0.63 \\
Minimum & 0.95 & 0.88 & 0.93 \\
Maximum & 53 & 41 & 95 \\
& 196 & 170 & 224 \\
\hline
\end{tabular}

TABLE 7

Correlations between Sense of Coherence, Internal Locus of Control, External Locus of Control, Autonomy and Stress

\begin{tabular}{lrrr}
\hline & \multicolumn{3}{c}{ STRESS } \\
\cline { 2 - 4 } PREDICTORITERION VARIABLE) \\
\cline { 2 - 4 } & $\mathbf{r}$ & $\mathbf{p}$ (two-tailed) & $\mathbf{N}$ \\
\hline Sense of Coherence & -0.58 & $<0.001$ & 233 \\
Internal Locus of Control & -0.22 & 0.001 & 240 \\
External Locus of Control & 0.35 & $<0.001$ & 240 \\
Autonomy & -0.36 & $<0.001$ & 240 \\
\hline
\end{tabular}

\section{Autonomy}

The responses of the present sample of employees are summarised in Table 6 . This scale consists of 34 seven-point items ranging from a minimum of 34 to a maximum of 238 . Jackson and Rothmann (2001) reported a mean autonomy score of 141.73 , with a standard deviation of 13.10 for 101 participants from the South African Police Service. As the distribution of the scores of the 240 participants is slightly negatively skewed (skewness $=-0.46$ ) and the median is 175 (mean $=170.10$, $\mathrm{SD}=28.99)$, it is clear that most of the participants reported relatively high levels of autonomy.

Relationships between sense of coherence, internal locus of control, external locus of control, autonomy and stress

Product moment correlations between the predictor variables sense of coherence and different dimensions of locus of control (namely internal locus of control, external locus of control and autonomy) and the criterion variable stress were calculated with the Statistical Package for Social Scientists (SPSS). There are inverse relationships (as is evident from the statistically significant negative correlation coefficients displayed in Table 7) between sense of coherence, internal locus of control and autonomy and the criterion variable stress. There is a direct relationship $(\mathrm{r}=0.35, \mathrm{p}<0.001)$ between external locus of control and stress (see Table 7).

A stepwise regression analysis, which included the predictor variables sense of coherence, the different dimensions of locus 
TABLE 8

Summary statistics of Stepwise regression of predictor variables Sense of Coherence and External Locus of Control on Stress ${ }^{c}$

\begin{tabular}{|c|c|c|c|c|c|c|c|c|c|}
\hline \multirow[b]{2}{*}{ MODEL } & \multirow[b]{2}{*}{$\mathbf{R}$} & \multirow[b]{2}{*}{$\mathbf{R}^{2}$} & \multirow[b]{2}{*}{$\begin{array}{r}A D J . \\
R^{2}\end{array}$} & \multirow[b]{2}{*}{$\begin{array}{l}\text { ERROR } \\
\text { OF EST. }\end{array}$} & \multicolumn{4}{|c|}{ CHANGE STATISTICS } & \multirow[b]{2}{*}{$\begin{array}{l}\text { DURBIN- } \\
\text { WATSON }\end{array}$} \\
\hline & & & & & $\mathbf{R}^{2}$ & $\mathbf{F}$ & 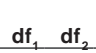 & Sig. $F$ & \\
\hline 1 & $0.59^{\mathrm{a}}$ & 0.35 & 0.34 & 18.61 & 0.35 & 121.57 & 1231 & $<0.001$ & \\
\hline 2 & $0.60^{\mathrm{b}}$ & 0.36 & 0.36 & 18.40 & 0.02 & 6.35 & 1230 & 0.012 & 1.81 \\
\hline
\end{tabular}

of control (namely internal locus of control, external locus of control and autonomy) and the criterion variable stress, was performed with the SPSS. Despite the significant correlations between the predictor variables and the criterion variable (as reported in Table 7), the stepwise regression analysis showed that only sense of coherence and external locus of control contributed significantly to the variance in stress (see Table 8). Sense of coherence and external locus of control explain about $36 \%$ of the variance in stress $\left(\mathrm{R}^{2}=0.36\right.$, see Table 8$)$. Of these variables, sense of coherence explains about 35\% (Table 8: Model 1 change- $R^{2}=0.35$ ), while the addition of external locus of control contributes about $2 \%$ (Table 8: Model 2 change- $R^{2}=0.02$ ) to the variance of stress. As the Durbin-Watson value of 1.81 is close enough to 2 (cf. Field, 2000), the correlation between the predictor variables are not large enough to be of concern.

\section{DISCUSSION}

From existing research it is clear that stress is quite common in South African society at large, but also in organisations specifically (Cilliers \& Kossuth, 2002; Dhaniram, 2003; Oosthuizen, 2006; Van Zyl \& Bester, 2002). Factors such as political and economic uncertainty, large scale restructuring, affirmative action and empowerment deals also contribute to a large degree to feelings of uncertainty (Shevel, 2007). Furthermore, if one takes into consideration that the present study was conducted in a parastatal organisation and that a large percentage of the participants were male $(66 \%)$ and white $(48 \%)$, one would expect them to report high levels of stress. This comment is based on the fact that white males are not considered to be a "designated group" in terms of the Employment Equity Act No. 55 of 1998. Nevertheless, most of the participants actually displayed relatively moderate levels of stress.

Stress is "an adaptive response" (Luthans, 2002 p. 396) and in terms of the salutogenic model, individuals may employ coping mechanisms such as sense of coherence and locus of control to manage their stress levels. Therefore one would expect individuals with a relatively strong sense of coherence to cope better with stress and therefore to have relatively low stress scores, while those with a weaker sense of coherence would have relatively high stress scores. This implies that there would be an inverse relationship between the variables sense of coherence and stress, which conclusion is supported in the present study by the significant negative correlation $(\mathrm{r}=-0.58$, $p<0.001$ ) between the relevant variables. Given these results, it also comes as no surprise that the sense of coherence of the present sample is quite strong with a median value of 133 in relation to the mean of 131 of a comparative group.

As a sense of exercising control over a stressful situation facilitates coping with stress (cf. Fontaine et al., 1993; Rosenbaum \& Jaffe, 1983), one would also expect individuals with high levels of internal locus of control and autonomy to report lower levels of stress and conversely those with lower scores on internal locus of control and autonomy to report relatively high levels of stress. These inverse relationships between internal locus of control and stress $(r=-0.22, p=0.001)$ and autonomy and stress $(r=-0.36, p<0.001)$ are supported by significant negative correlations between the relevant variables.
In contrast to the findings about internal locus of control and autonomy, one would expect individuals reporting high levels of external locus of control to experience relatively high levels of stress and those with low external locus of control scores to receive relatively low stress scores. There would therefore be a direct relationship between the variables external locus of control and stress, which inference is supported by the statistically significant correlation $(\mathrm{r}=0.35, \mathrm{p}<0.001)$ between the relevant variables.

The present design is relational and as such one cannot infer causality from the correlations between the variables because the design does not allow one to determine which variables are antecedents and which consequents. However, using regression analysis it is possible to determine which variables may act as predictors of a criterion.

In terms of the salutogenic model and taking the significant correlations between the salutogenic variables and stress into consideration, one would expect all relevant variables to contribute to the prediction of the criterion variable stress. As sense of coherence refers to individuals' feeling of confidence in dealing with external and internal environments, the present findings indicate that individuals with a strong sense of coherence feel that they are able to manage their stress while those with a weaker sense of coherence are not managing well.

The direct relationship between external locus of control and stress indicates that individuals who feel that control over situations is largely located externally to themselves are experiencing high levels of stress, while those who feel that control is not located externally are experiencing lower levels of stress.

In terms of literature (Oosthuizen, 2006; Rotter, 1966; 1990) and given the significant correlations between internal locus of control and stress and autonomy and stress in the present study, one would expect individuals who have a strong internal locus of control and a high level of autonomy to be able to manage stress effectively. Therefore one would expect these variables to serve as predictor variables to the criterion stress in the regression model. However, they do not contribute significantly to the variance in stress and as such were excluded from the stepwise regression model.

The researchers have argued above that the salutogenic model could be seen as part of Hart and Cooper's (2001) comprehensive process model of managing stress. Given the statistically significant correlations between the different dimensions of locus of control and stress, one would expect that, similar to sense of coherence and external locus of control, the other dimensions (internal locus of control and autonomy) also contribute to the variance of the criterion variable stress. However, this did not happen. A possible explanation may be that the relationships between the relevant variables are too complex to investigate in a piecemeal fashion with regression analysis. Perhaps one should include more variables and use a more powerful analysis tool, such as structural equations modelling, to investigate a variety of models.

Although stress in not necessarily damaging, if left unchecked, it could result in increased costs to the organisation and individual (cf. Morris, 2004; Shevel, 2007). Adams (2007) writes that individuals who feel that they have a great degree of control over their surroundings would feel more comfortable and would be affected less by environmental stressors. Consequently, Adams (2007) recommends allowing employees more scope to control their own work environment, which in turn can contribute to a reduction in their stress levels. Essentially it means that organisations should create a work environment in which employees are allowed to function salutogenically and as a result succeed in managing their stress effectively. 


\section{REFERENCES}

Adams, J. (2007). Managing people in organizations: Contemporary theory and practice. Houndmills, UK: Parlgrave Macmillan.

Antonovsky, A. (1979). Health, stress and coping. San Francisco: Jossey-Bass.

Antonovsky, A. (1987). Unravelling the mystery of health: How people manage stress and stay well. San Francisco: Jossey-Bass.

Atkinson, W. (2004). Stress: Risk management's most serious challenge? Risk Management, 51, 20-26.

Cilliers, F. \& Kossuth, S. (2002). The relationship between organisational climate and salutogenic functioning. South African Journal of Industrial Psychology, 28, 8-13.

Dhaniram, N. (2003).Stress, burnoutand salutogenicfunctioning amongst community service doctors in Kwazulu-Natal hospitals. Unpublished master's thesis, University of South Africa, Pretoria, South Africa.

Employment Equity Act No. 55. (1998, October 19). Government Gazette Vol. 400, No. 19370. Cape Town.

Field, A. (2000). Discovering Statistics Using SPSS for Windows: Advanced Techniques for the Beginner. London: Sage.

Flannery, R.B. \& Flannery, G.J. (1990). Sense of coherence, life stress and psychological distress: A prospective methodological inquiry. Journal of Clinical Psychology, 46(4), 415-420.

Florian, V., Mikulincer, M. \& Taubman, O. (1995). Does hardiness contribute to mental health during a stressful real-life situation? The roles of appraisal and coping. Journal of Personality and Social Psychology, 68(4), 687-695.

Fontaine, K.R., Manstead, A.S.R. \& Wagner, H. (1993). Optimism, perceived control over stress and coping. European Journal of Personality, 7, 267-281.

Hart, P.M. \& Cooper, C.L. (2001). Occupational stress: Toward a more integrated framework. In N. Anderson, D.S. Ones, H.K. Sinangil \& C. Viswesvaran (Eds.). Handbook of industrial, work and organizational psychology: Vol. 2. Organizational psychology (pp. 93-114). London: Sage.

Jackson, L. \& Rothmann, S. (2001). Sense of coherence, selfefficacy, locus of control as predictors of job satisfaction. Poster presented at the $10^{\text {th }}$ European Congress on Work and Organisational Psychology, Prague, Czech Republic

Kobasa, S.C. (1979). Stressful life events, personality and health: An enquiry into hardiness. Journal of Personality and Social Psychology, 37(1), 1-11.

Kossuth, S.P. \& Cilliers, F. (2002). The relationship between leadership dimensions, cultural beliefs and salutogenic functioning. South African Journal of Labour Relations, 26(1), 65-95.

Kravetz, S., Drory, Y. \& Florian, V. (1993). Hardiness and sense of coherence and their relation to negative affect. European Journal of Personality, 7, 233-244.

Le Feure, M., Matteny, J. \& Kolt, G.S. (2003). Eustress, distress and interpretation in occupational stress. Journal of Managerial Psychology, 18, 726-744.

Lowe, G.S. (2004). Creating healthy productive organisations. The Journal of Employee Assistance, 34, 7-10.

Luthans, F. (2002). Organizational behavior (9th ed.). Boston: McGraw-Hill Irwin.
Morris, B.A. (2004). Stress test 2004. Risk and Insurance, 14, 32-34.

Oosthuizen, J. (2006). The relationship between stress and salutogenic functioning amongst employees in a state owned enterprise. Unpublished master's thesis, University of the Western Cape, Bellville, South Africa.

Pretorius, W. (2004). Organisational factors influencing the transformational process of a financial institution. Unpublished doctoral thesis, University of Pretoria, Pretoria, South Africa.

Recupero, C.M. (2003). Enhancing organisational safety through stress management. The Journal of Employee Assistance, 33, 26-28.

Rosenbaum, M. (1980). A schedule for assessing self-control behaviors: Preliminary findings. Behavior Therapy, 11(11), 109-121.

Rosenbaum, M. (1988). Learned resourcefulness, stress and self-regulation. In S. Fisher \& J. Reason (Eds.). Handbook of life-stress, cognition and health (pp. 483-496). Chichester: John Wiley.

Rosenbaum, M. \& Jaffe, Y. (1983). Learned helplessness: The role of individual differences in learned resourcefulness. British Journal of Social Psychology, 22, 215-225.

Rotter, J. 1966). Generalized expectations of internal versus external control of reinforcements. Psychological Monographs, 80(1), 1-28.

Rotter, J. (1990). Internal versus external control of reinforcements: A case history of a variable. American Psychologist, 45(4), 489-493.

Schepers, J.M. (2005). Technical manual: Locus of Control Inventory. Unpublished manuscript, University of Johannesburg, Johannesburg, South Africa.

Shevel, A. (2007, July 22). Work disability payouts in SA are all in the head. Sunday Times, Business Times, p. 11.

Smith, D.F. (2002). Functional salutogenic mechanisms of the brain. Perspectives in Biology and Medicine, 45, 319-328.

Van Zyl, E. \& Bester, C. (2002). 'n Vergelykende studie na die vlak en oorsake van werkstres by 'n groep geletterde en ongeletterde swart werknemers (A comparative study of the level and causes of occupational stress among groups of skilled and unskilled black employees). South African Journal of Industrial Psychology, 27(3), 19-23.

Van Zyl, E.S. \& Van der Walt, H.S. (1991). Manual for the Experience of Work and Life Circumstances Questionnaire (WLQ). Pretoria: Human Sciences Research Council.

Van Zyl, E.S. \& Van der Walt, H.S. (1994). Manual for the Experience of Work and Life Circumstances Questionnaire (WLQ). Bloemfontein.

Viviers, A.M. (1998a). Stress: Identifying non-copers and helping them. Management Today, 14(7), 38-39.

Viviers, A.M. (1998b). Stress: Is there anything positive about it? Management Today, 14(7), 42-43.

Viviers, A.M. \& Cilliers, F. (1999). Die verband tussen salutogenese en werkoriëntasie (The relationship between salutogenesis and work orientation). South African Journal of Industrial Psychology, 25(1), 27-32. 